\title{
RAYLEIGH-PLATEAU DISSIPATIVE INSTABILITY
}

\author{
(D)oksana L. Andrieieva ${ }^{\mathrm{a}, \mathrm{b}}$, (D) Leonid A. Bulavin ${ }^{\mathrm{c}} * *$, (D) Viktor I. Tkachenko ${ }^{\mathrm{a}, \mathrm{b} *}$ \\ ${ }^{a}$ NSC "Kharkiv Institute of Physics and Technology" \\ Academichna Str. 1, 61108, Kharkiv, Ukraine \\ ${ }^{b}$ V.N. Karazin Kharkiv National University, Kharkiv, Ukraine \\ 4 Svobody Sq., 61022, Kharkiv, Ukraine \\ *Corresponding Author: andreevaoksana@kipt.kharkov.ua \\ ${ }^{c}$ Taras Shevchenko National University of Kyiv \\ 64/13, Volodymyrska Str., 01601, Kyiv, Ukraine \\ **Corresponding Author: bulavin221@gmail.com \\ Received November 22, 2020; accepted March 30, 2020
}

The instability of a freely falling jet of liquid in air taking into account the viscosity of the contacting media is considered. In neglecting the viscosities of both media, instability was studied by Rayleigh and Plateau. They showed that instability develops as a result of the action of surface forces, and is expressed in a change in the cylindrical shape of the boundary of a freely falling jet of liquid with air into a sequence of spherical drops. In subsequent works, by phenomenological consideration of viscosity by means of the Ohnesorge number, it is shown that the viscosity of each of the contacting media affects the nature of the instability. However, this method of taking viscosity into account is not entirely correct, because does not take into account the specificity of the boundary conditions existing at the interface. It is proposed to use percolation boundary conditions, the validity of which is proved by the example of the exact determination of the threshold velocity of occurrence of Kelvin-Helmholtz instability. A dispersion equation of the Rayleigh-Plateau problem with percolation boundary conditions that describes the instability taking into account the viscosity of both media is obtained. The dissipative nature of the development of such instabilities is substantiated. The growth rates of instabilities are determined in cases when: the jet and medium have a low viscosity (ideal fluids); the jet is characterized by high viscosity, and the environment is small; the jet and the environment are highly viscous. It is shown that the theoretical model of droplet decay of the jet in the absence of viscosity of both media is quite good, in quantitative terms, consistent with experimental results. The maximum increment is equal $\gamma_{K G}^{\max } \approx 0.32$, against the Rayleigh-Plateau increment $\gamma_{R P}^{\max } \approx 0.34$, for disturbances with the same wave number $X_{\max } \approx 0.7$. It was also shown that for viscous jets and a weakly viscous environment, the instability increment describes the experimental results with a rather high degree of accuracy. Numerical calculations show that for jets of comparable viscosity, the instability increment decreases with increasing viscosity of the environment. If the viscosity of the environment is constant, then the increment of instability will be greater where the viscosity of the stream is higher. It is shown that the results of theoretical calculations are in good agreement with the available experimental data.

KEYWORDS: Rayleigh-Plateau instability, surface tension, viscosity, percolation boundary conditions, dissipative instability, instability increment, wave number, instability range.

In the classical formulation the Rayleigh-Plateau problem is associated with a study of the hydrodynamic instability of the cylindrical boundary of a freely falling jet of liquid with respect to its decomposition into separate droplets.

Joseph Plateau first observed and characterized this instability in 1873 [1]. He noted that the instability occurred when the liquid column length $\lambda$ exceeded the column diameter $D=2 R_{0}$ by a factor of about 3.13 , i.e. when the condition $\lambda \geq 3.13 \cdot 2 R_{0}$ was satisfied. Later lord Rayleigh corroborated the Plateau's work results by theory giving an analytical description of this physical phenomenon [2, 3]. He showed that such an unstable behavior of a jet was due to the availability of small perturbations on its surface, which could increase at certain wavelengths. Rayleigh showed that sinusoidal perturbations of the surface were unstable due to effect of surface forces. However, the criterion for instability development defined by him differs from Plato's criterion and takes the following form $\lambda \geq 4.51 \cdot 2 R_{0}$. Taking account of the formation of small intermediate droplets between the main droplets leads to a slight decrease in the unstable wavelength to the value of $\lambda \geq 4.42 \cdot 2 R_{0}$ [4]. However, such a decrease does not violate the general conclusions regarding the criterion for the development of instability, which has been confirmed with a sufficient degree of reliability by a significant number of experiments [5].

The physical phenomenon under consideration has a simple physical substantiation. The process of decomposition the ow into droplets is due to the need of the system to occupy a position with the minimum potential energy. And since in a free state a fixed cylindrical volume of a liquid is subject to surface tension forces, it will tend to take a spherical shape that has a minimal surface and, therefore, the minimum potential energy of capillary forces [6]. The above mentioned refers to a cylindrical liquid jet that is unstable with respect to its decomposition into droplets. However, the list of such processes in the ambient environment is much longer [5]. Study of such processes is motivated not only by their practical application, but also by a scientific content. The latter should include the definition of physical mechanisms leading to decomposition of jets under various conditions, as well as the description of the effect of surface 
tension and viscosity on the dynamics of processes. And if the surface tension is the basis of instability, then viscous forces can lead to a change in the characteristic decomposition times without changing the limits in which the stability of the system is observed [5].

As a rule, the viscosity in problems of jet stability is taken into account phenomenologically by introducing, along with the jet radius $R_{0}$, a new characteristic length, called the "penetration depth". This length is determined by the Ohnesorge number $O h=v \sqrt{\rho / \sigma R_{0}}$ [7] and has the form: $l_{O h}=\sqrt{v / \omega}$ where $v$ - the coefficient of kinematic viscosity, $\rho$ - the liquid density, $\sigma$ - the coefficient of surface tension.

Comparison of the Rayleigh theory for jets with no viscosity, as well as the Rayleigh-Chandrasekhar theory in viscous media with experimental data [5] indicates a certain agreement. In some cases, the issue of agreement remains open due to the lack of measurement error data in [5]. Therefore, the method of taking account of the viscosity of media by means of the Ohnesorge number is not entirely correct, since it does not take into account the specifics of the boundary conditions at the media interface.

If we consider the liquid jet and the surrounding air as two contacting media with their characteristic parameters, then the Rayleigh problem [2,3] transforms into the Kelvin-Helmholtz problem [8, 9]. In this case, as shown in [10], the jet instability increment can be obtained from the Kelvin-Helmholtz instability increment, assuming the gravity force equal to zero. At the same time, as shown in [11], only the use of percolation boundary conditions makes it possible to take into account the viscosity of both media, to determine the threshold number and the increment of instability development. Under this approach the threshold velocity of instability development coincides with the experimentally measured. Therefore, on the basis of the foregoing in the present work we consider the Rayleigh-Plateau problem within the framework of the Kelvin-Helmholtz model of instability development, taking into account the viscosity of both media and using percolation boundary conditions.

For further research of the Rayleigh-Plateau problem we will turn our attention to the obtained experimental results. So, in the experimental implementation of the Rayleigh-Plateau problem a liquid jet from a pipe of a certain radius is falling vertically under gravity. Initially, at the exit of the pipe, the jet has a constant radius equal to the radius of the pipe. The length of the falling liquid jet increases and reaches such a critical value, when the jet loses its cylindrical shape as a result of decomposition into a sequence of droplets of almost the same size. Capillary instability of a liquid jet owing under pressure from a pipe of diameter $D=4 \mathrm{~mm}$ is presented in Fig 1. The initial sonic perturbations superimposed on the jet had a wavelength of $\lambda=168 \mathrm{~mm}, 50 \mathrm{~mm}$ and $18.4 \mathrm{~mm}$. Their effect on the jet stability during the motion from top to bottom, respectively, is shown in Fig. 1 [12]. The figure shows that the last value of the wavelength is closest to the value of $\lambda / D>3.13$ found by Joseph Plato.

To understand the physical phenomena underlying the droplet instability of a cylindrical free-falling jet we present below the result of study of the instability of freely falling jet decomposition into droplets obtained by Rayleigh $[2,3]$.

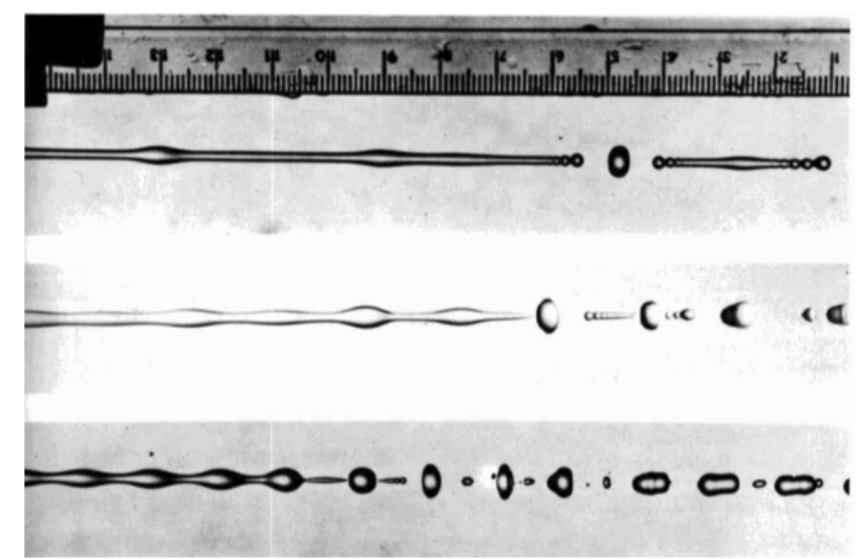

Figure 1. Capillary instability of a liquid jet owing under pressure from a pipe with a diameter of $D=4 \mathrm{~mm}$. The initial perturbations of the jet shape are initiated by sound waves of a wavelength equal to 42, 12.5 and 4.6 of the pipe diameter [12].

\section{THE RAYLEIGH'S PROBLEM}

Rayleigh investigated the stability of boundary of a cylindrical liquid jet of radius $R_{0}$, density $\rho$ and surface tension $\sigma$ in a cylindrical coordinate system $r, \phi, z$, where the axes $\phi$, z were parallel to the interface and the axis $z$ was oriented vertically upwards. As the values, describing the stability of the liquid boundary, he chose radial $-W_{r}$ and vertical $-W_{z}$ perturbation of liquid velocity, displacement of liquid interface $\varepsilon(r, \phi, z, t)$ from the equilibrium position $R_{0} R(r, z, t)=R_{0}+\varepsilon(r, z, t) ; \quad|\varepsilon|<<R_{0} \quad$ and deviation of liquid pressure from equilibrium $p_{0}$ $p(r, z, t)=p_{0}+\tilde{p}(r, z, t), \quad|\tilde{p}|<p_{0}$. 
For small axially symmetric perturbations of the form

$$
\begin{aligned}
& W_{r}=U_{r}(r) \exp (-i \omega t+i k z) ; \quad W_{z}=U_{z}(r) \exp (-i \omega t+i k z) ; \\
& \tilde{p}=P(r) \exp (-i \omega t+i k z) ; \quad \varepsilon=\varepsilon_{0}(r) \exp (-i \omega t+i k z) .
\end{aligned}
$$

where, $\omega$ and $k=\frac{2 \pi}{\lambda}$ - the frequency and the wavenumber of the interface perturbation, respectively, $\lambda$ - wavelength of the perturbation, the dispersion equation has the form $[2,3]$ :

$$
\omega^{2}=-\left(1-k^{2} R_{0}^{2}\right) \frac{\sigma k}{\rho R_{0}^{2}} \frac{I_{1}\left(k R_{0}\right)}{I_{0}\left(k R_{0}\right)} .
$$

where, $I_{0}(x), I_{1}(x)$ modified Bessel's functions of the first kind of the zero and the first order, respectively [13].

It follows from (2) that the instability arises for negative values of the square of the frequency $\omega^{2}<0$, i.e. when $k R_{0}<1$. In this case the radius perturbation increases with increment:

$$
\gamma_{R P}(K)=\Gamma_{0} \sqrt{\left(1-K^{2}\right) K \frac{I_{1}(K)}{I_{0}(K)}}
$$

where, $\varepsilon \sim \exp \left(\gamma_{R P} t\right)$ variation of the liquid boundary displacement in time, $\Gamma_{0}=\sqrt{\frac{\sigma}{\rho R_{0}^{3}}} 0, K=k R_{0}-$ dimensionless wave number.

From the condition $K>1$ it follows that the instability is possible when the length of the working circle of the jet is less than the perturbation wave length in vertical direction. Calculations (3) gives the maximum increment is equal to $\gamma_{R P}^{\max }=0.343 \sqrt{\sigma / \rho R_{0}^{3}}$ and is reached at $K=0.7$. For example, for a water jet of $10 \mathrm{~cm}$ in diameter at the surface tension coefficient $\sigma=72.58 \mathrm{erg} / \mathrm{cm}^{2}$ (at a temperature of $20^{\circ} \mathrm{C}$ ) and density $\rho=1 \mathrm{~g} / \mathrm{cm}^{3}$ [14], the characteristic time of jet decomposition into droplets is about of order:

$$
\left(\gamma_{R P}^{\max }\right)^{-1}=2.91 \sqrt{\frac{\rho R_{0}^{3}}{\sigma}}=2.91 \sqrt{\frac{5^{3}}{72.58}}=3.82 \mathrm{~s} .
$$

From (3) follows that if the radius of the jet decreases the characteristic decomposition time decreases. For water jet of $1 \mathrm{~mm}$ in diameter this time will be $3.8 \mathrm{~ms}$. Let us compare the obtained expression for the increment (3) with the experimental data given in Fig. 1. It follows from the figure that the last value of the sound wave length does not coincide with, but it is most closely to the Rayleigh value: $K=0.7=2 \pi R_{0} / \lambda \rightarrow \lambda=6.28 \cdot 0.2 / 0.7=1.79 \mathrm{~cm}$, which is about $1.25 \mathrm{~cm}$ in the experiment. Comparing theory with experiment there is a slight mismatch of theoretical conclusions with experimental data. Therefore, there is a need to find models that would eliminate this discrepancy. In the next section a model for describing the instability of jet decomposition into droplets based on the Kelvin-Helmholtz theory of instability is proposed, which takes into account surface tension, viscosity of both media and uses percolation boundary conditions.

\section{RAYLEIGH-PLATEAU INSTABILITY IN THE FORMULATION OF THE KELVIN-HELMHOLTZ PROBLEM WITH PERCOLATION BOUNDARY CONDITIONS}

Let us consider the problem of stability of a liquid jet owing freely from a pipe in the formulation of the Kelvin-Helmholtz problem. Oscillation of the interface between two media with density $\rho_{1}, \rho_{2}$ and coefficients of dynamic viscosity $\mu_{1}, \mu_{2}$ in a cylindrical coordinate system $\rho, \phi, z$ (axes $\phi, z$ are parallel to the interface, the axis $z$ is oriented vertically upwards) we will describe using three functions: two functions for the velocity potentials $\varphi_{1,2}(r, \phi, z, t)$, the function of the liquid interface displacement from the equilibrium position, where the perturbed radial position of the interface $R(r, \phi, z, t)$ is determined by expression (1). As in the previous section, due to the axial symmetry of the problem we assume the perturbed values independent of the azimuth angle $\phi$. With this consideration the velocity of the fluid in media 1,2 is determined by the expression: $\vec{W}_{1,2}=\vec{\nabla} \varphi_{1,2}(r, z, t)=\vec{\nabla}\left(\varphi_{1,2}^{(0)}(z)+\tilde{\varphi}_{1,2}(r, z, t)\right)$, where $\varphi_{1,2}^{(0)}(z)$ - the potential of liquid velocities in the equilibrium state; $\tilde{\varphi}_{1,2}(r, z, t)$ - the potential of the disturbed velocity of the medium 1,$2 ; \tilde{\varphi}_{1,2}(r, z, t)$ - operator of gradient in a cylindrical coordinate system; $\left|\varphi_{1,2}^{(0)}(z)\right|>>\left|\tilde{\varphi}_{1,2}(r, z, t)\right|$ - the smallness disturbance condition. The location of viscous media and the boundaries 
between them are schematically presented in Fig.2. The boundary of viscous media is determined by the expression $R=R_{0}+\varepsilon(r, z, t)$ and the media move at different velocities $\vec{V}_{1,2}$ parallel to the axis $z$.

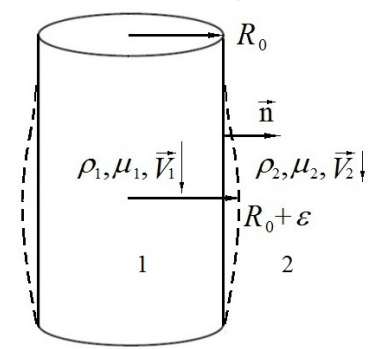

Fig. 2. The layout diagram of the interface of viscous media $R=R_{0}+\varepsilon(r, z, t)$ moved at different velocities $\vec{V}_{1,2}$, parallel to the axis $z$

For the case shown in Fig. 2 the potential of the equilibrium velocity can be represented as:

$$
\varphi_{1,2}^{(0)}(z)=V_{1,2} z+C_{1,2}
$$

where, $C_{1,2}$ - constant.

The equations for functions $\varphi_{1,2}(r, z, t)$ and $\varepsilon(r, z, t)$ are well known [15], they consist of the equation for the incompressibility of a liquid and the equation describing the kinematic boundary condition. The equation for the liquid incompressibility is as follows:

$$
\Delta \tilde{\varphi}_{1,2} \equiv \Delta_{\perp} \tilde{\varphi}_{1,2}+\frac{\partial^{2} \tilde{\varphi}_{1,2}}{\partial z^{2}}=0
$$

where, $\Delta \ldots=\frac{1}{r} \frac{\partial}{\partial r} r \frac{\partial \ldots}{\partial r}+\frac{\partial^{2} \ldots}{\partial z^{2}}=\Delta_{\perp} \ldots+\frac{\partial^{2} \ldots}{\partial z^{2}}$. The potential of the equilibrium velocity of the medium (5) automatically satisfies the equation (6). In further calculations we omit the sign for the convenience of writing. The kinematic boundary condition determines the radial velocity of the liquid at media interface:

$$
\frac{d R}{d t}=\left(W_{1,2}\right)_{r}=\frac{\partial \tilde{\varphi}_{1,2}}{\partial r} ; \quad \frac{\partial R}{\partial t}+\left[\left(\vec{W}_{1.2} \vec{\nabla}\right) \vec{R}\right]_{r}=\frac{\partial \tilde{\varphi}_{1,2}}{\partial r}
$$

After linearization (7) we have:

$$
\left.\frac{\partial \varepsilon}{\partial t}\right|_{r=R_{0}+\varepsilon(r, z, t)}+\left.V_{1,2} \frac{\partial \varepsilon}{\partial z}\right|_{r=R_{0}+\varepsilon(r, z, t)}=\left.\frac{\partial \tilde{\varphi}_{1,2}}{\partial r}\right|_{r=R_{0}+\varepsilon(r, z, t)}
$$

Equations (6), (8) should be supplemented by a dynamic boundary condition. This condition can be obtained by integrating along the coordinate $r$ of the radial component of the linearized Navier-Stokes equation:

$$
\vec{T}=\rho\left(\frac{\partial \vec{W}}{\partial t}+(\vec{W} \vec{\nabla}) \vec{W}\right)+\vec{\nabla} p=0
$$

over a thin transition boundary layer $-\Delta \leq r-R_{0}-\varepsilon\left(R_{0}, z, t\right) \leq \Delta$, according to the expression:

$$
\lim _{\substack{\Delta \rightarrow 0 \\ \varepsilon \rightarrow 0}}\left(\int_{r=R_{0}+\varepsilon\left(R_{0}, z, t\right)-\Delta}^{r=R_{0}+\varepsilon\left(R_{0}, z, t\right)+\Delta}\left(T_{r}\right) d r\right)=\lim _{\Delta \rightarrow 0}\left(\int_{r=R_{0}-\Delta}^{r=R_{0}+\Delta}\left(T_{r}\right) d r\right)
$$

Let us obtain this dynamic boundary condition. To simplify the procedure of integration over a thin transition layer we present the coefficient of dynamic viscosity of both media $\mu(r)$ in the following model form:

$$
\begin{aligned}
& \mu(r)=\mu_{1} \theta\left(-r+R_{0}-\Delta\right)+\mu_{2} \theta\left(r-R_{0}-\Delta\right)+ \\
& +\left(\mu_{1}+\mu_{2}\right)\left(\theta\left(r-R_{0}+\Delta\right)-\theta\left(r-R_{0}-\Delta\right)\right),
\end{aligned}
$$

where, $\theta(x)$ - asymmetric unit function $\theta(x)=1$ at $x \geq 0$ and $\theta(x)=0$ at $x<0$. When obtaining a dynamic boundary condition, the model dependence (11) characterizes its percolation boundary conditions [11]. The physical nature of "percolation boundary conditions" is the effect of the mutual periodic penetration of contacting media near the interface in areas not previously occupied by them. Such penetration of media is taken into account by a model representation of the viscosity coefficient at the interface in the form of stepwise functions of the radius. The proposed 
model representation is valid, because in the Kelvin-Helmholtz instability problem with a at boundary [15], the use of a viscosity coefficient in the form of superimposed steps of the form (11) leads to the dispersion equation, which gives a threshold ow velocity corresponding to the experimental one. After linearization the Navier-Stokes equation (9) takes the form:

$$
\rho\left(\frac{\partial}{\partial t} \frac{\partial \tilde{\varphi}}{\partial x_{k}}+\frac{1}{2} \frac{\partial}{\partial x_{k}}\left(\frac{\partial\left(\varphi^{(0)}(z)+\tilde{\varphi}\right)}{\partial x_{i}}\right)^{2}\right)-\left(2 \frac{\partial \mu(r)}{\partial r} \frac{\partial^{2} \tilde{\varphi}}{\partial r^{2}}+2 \mu(r) \frac{1}{r^{2}} \frac{\partial \tilde{\varphi}}{\partial r}\right)+\frac{\partial p}{\partial x_{k}}=0
$$

where, $k=r, i=r, z, x_{r}=r, x_{z}=z$, the corresponding term should be summed on index " $i "$.

For the selected model dependence of the medium viscosity $\mu(r)$ upon the coordinate $z$ the main contribution to the dynamic boundary condition makes a summand proportional to $\partial \mu(z) / \partial z$. Integrating (12) over a thin transition layer $\left(R_{0}-\Delta, R_{0}+\Delta\right)$ along the radius, taking into account (8), and then tending to zero $\Delta \rightarrow 0$, we obtain the following dynamic boundary condition:

$$
\left.\rho\left(\frac{\partial}{\partial t} \tilde{\varphi}+V_{1,2} \frac{\partial \tilde{\varphi}}{\partial z}\right)\right|_{1} ^{2}+\left.2\left(\frac{1}{r} \frac{\partial}{\partial r}+\frac{\partial^{2}}{\partial z^{2}}\right)\right|_{\mu_{2} \tilde{\varphi}_{1}} ^{-\mu_{1} \tilde{\varphi}_{2}}+\left.p\right|_{1} ^{2}+\sigma \frac{\partial^{2} \varepsilon}{\partial z^{2}}=\text { const }
$$

In (13) the pressure difference corresponds to the Bernoulli equation and is determined by the expression: $\left.p\right|_{1} ^{2}=p_{2}-p_{1}=$ const, where, const $=\rho_{2} \frac{V_{2}^{2}}{2}-\rho_{1} \frac{V_{1}^{2}}{2}$.

Thus, we have a system of equations for perturbed values on the jet boundary:

$$
\begin{gathered}
\Delta_{\perp} \tilde{\varphi}_{1,2}+\frac{\partial^{2} \tilde{\varphi}_{1,2}}{\partial z^{2}}=0 \\
\left.\frac{\partial \varepsilon}{\partial t}\right|_{r=R_{0}}+\left.V_{1,2} \frac{\partial \varepsilon}{\partial z}\right|_{r=R_{0}}=\left.\frac{\partial \tilde{\varphi}_{1,2}}{\partial r}\right|_{r=R_{0}}, \\
\left.\rho\left(\frac{\partial}{\partial t} \tilde{\varphi}+V_{1,2} \frac{\partial \tilde{\varphi}}{\partial z}\right)\right|_{1} ^{2}+\left.2\left(\frac{1}{r} \frac{\partial}{\partial r}+\frac{\partial^{2}}{\partial z^{2}}\right)\right|_{\mu_{2} \tilde{\varphi}_{1}} ^{-\mu_{1} \tilde{\varphi}_{2}}+\sigma \frac{\partial^{2} \varepsilon}{\partial z^{2}}=0 .
\end{gathered}
$$

We'll submit the velocity potentials $\tilde{\varphi}$ and the interface displacement $\varepsilon$ in the form of $\tilde{\varphi}_{1,2} \sim f_{1,2}(r) \exp (i k z-i \omega t), \varepsilon \sim g(r) \exp (i k z-i \omega t)$, where $\omega$ and $k$ are the frequency and the wavenumber of the wave, $k=2 \pi / d, d$ - the perturbation wavelength along the jet axis. Then from equation (14) we obtain a radiusrestricted solution for a perturbed velocity potential $f_{1}(r)$ in medium 1 and an infinity-restricted solution for a perturbed velocity potential in medium 2 :

$$
\begin{aligned}
& f_{1}(r)=A I_{0}(k r), \quad 0 \leq r \leq R_{0} \\
& f_{2}(r)=B K_{0}(k r), \quad R_{0} \leq r \leq \infty
\end{aligned}
$$

where, $I_{0}(x), K_{0}(x)$ - modified Bessel functions of the second kind of the zero order [13], $A, B$ - constants. From (15), (16) we obtain the system of equations:

$$
\begin{gathered}
-i\left(\omega-k V_{1}\right)=A k I_{1}\left(k R_{0}\right), \\
-i\left(\omega-k V_{2}\right)=-B k K_{1}\left(k R_{0}\right), \\
\left.\rho\left(\frac{\partial}{\partial t} \tilde{\varphi}+V_{1,2} \frac{\partial \tilde{\varphi}}{\partial z}\right)\right|_{1} ^{2}+\left.2\left(\frac{1}{r} \frac{\partial}{\partial r}+\frac{\partial^{2}}{\partial z^{2}}\right)\right|_{\mu_{2} \tilde{\varphi}_{1}} ^{-\mu_{1} \tilde{\varphi}_{2}}+\sigma \frac{\partial^{2} \varepsilon}{\partial z^{2}}=0 .
\end{gathered}
$$

where, $K_{1}(x)$ - modified Bessel function of the second kind of the first order [13].

Solution of equations (18) - (20) in the Lamb type reference system $\rho_{2} V_{2} K_{0}\left(k R_{0}\right) / K_{1}\left(k R_{0}\right)+\rho_{1} V_{1} I_{0}\left(k R_{0}\right) / I_{1}\left(k R_{0}\right)=0$ gives the following dispersion equation: 


$$
\begin{gathered}
\omega^{2}+2 i \omega \frac{\left(\mu_{1} k^{2}\left(1+k R_{0} \frac{K_{0}\left(k R_{0}\right)}{K_{1}\left(k R_{0}\right)}\right)+\mu_{2} k^{2}\left(1-k R_{0} \frac{I_{0}\left(k R_{0}\right)}{I_{1}\left(k R_{0}\right)}\right)\right)}{\left(\rho_{2} k R_{0} \frac{K_{0}\left(k R_{0}\right)}{K_{1}\left(k R_{0}\right)}+\rho_{1} k R_{0} \frac{I_{0}\left(k R_{0}\right)}{I_{1}\left(k R_{0}\right)}\right)}- \\
-2 i k^{3} \frac{\left(\mu_{1} V_{2}\left(1+k R_{0} \frac{K_{0}\left(k R_{0}\right)}{K_{1}\left(k R_{0}\right)}\right)+\mu_{2} V_{1}\left(1-k R_{0} \frac{I_{0}\left(k R_{0}\right)}{I_{1}\left(k R_{0}\right)}\right)\right)}{\left(\rho_{2} k R_{0} \frac{K_{0}\left(k R_{0}\right)}{K_{1}\left(k R_{0}\right)}+\rho_{1} k R_{0} \frac{I_{0}\left(k R_{0}\right)}{I_{1}\left(k R_{0}\right)}\right)}+ \\
+\frac{\rho_{2}\left(k V_{2}\right)^{2} k R_{0} \frac{K_{0}\left(k R_{0}\right)}{K_{1}\left(k R_{0}\right)}+\rho_{1}\left(k V_{1}\right)^{2} k R_{0} \frac{I_{0}\left(k R_{0}\right)}{I_{1}\left(k R_{0}\right)}-k^{4} R_{0} \sigma}{\left(\rho_{2} k R_{0} \frac{K_{0}\left(k R_{0}\right)}{K_{1}\left(k R_{0}\right)}+\rho_{1} k R_{0} \frac{I_{0}\left(k R_{0}\right)}{I_{1}\left(k R_{0}\right)}\right)}=0
\end{gathered}
$$

Let us consider the solution of equation (21) with no viscosity, i.e. assume $\mu_{1}=\mu_{2}=0$. In this case the equation (21) takes the form:

$$
Y(X, G)= \pm i \frac{X}{\sqrt{G}} \sqrt{\frac{\left(\frac{\rho_{2} V_{2}^{2}}{\rho_{1} V_{1}^{2}} \frac{K_{0}(X)}{K_{1}(X)} \frac{I_{1}(X)}{I_{0}(X)}+1\right)-G X \frac{I_{1}(X)}{I_{0}(X)}}{\left(\frac{\rho_{2}}{\rho_{1}} \frac{K_{0}(X)}{K_{1}(X)} \frac{I_{1}(X)}{I_{0}(X)}+1\right)}}
$$

where, $G=\frac{\sigma}{V_{1}^{2} \rho_{1} R_{0}}, X=k R_{0}, Y=\omega \sqrt{G} \sqrt{\frac{\rho_{1} R_{0}^{3}}{\sigma}}$

The instability increment is determined by the expression:

$$
\gamma_{K G}(X, G)=\operatorname{Im}(Y(X, G))
$$

and is realized at positive values of the radical expression (22).

The summands for water and air proportional to small values $\rho_{2} V_{2}^{2} / \rho_{1} V_{1}^{2}<<1$ and $\rho_{2} / \rho_{1}<<1$ can be neglected in (23). As a result, we come to the following expression for the instability increment:

$$
\gamma_{K G}(X, G)=\frac{X}{\sqrt{G}} \sqrt{1-G X \frac{I_{1}(X)}{I_{0}(X)}} .
$$

In (24) the constant $G$ is specified by the system parameters at the initial time. Let us determine its value. From experimental studies of jet decomposition into droplets with no viscosity it follows that instability is possible for $X \leq 1$ [5]. Therefore, from the condition of stability $\gamma_{K G}(1, G)=0$ it is easy to determine the value $G$ : $G=I_{0}(1) / I_{1}(1) \approx 2.24$.

We compare the obtained expression for the increment (24) with the experimental data shown in Fig. 1 as well as with those given in the review [5]. Let us consider first the experimental data in Fig. 1. But first of all we note that the excitation wavelengths prescribed in the experiment do not correspond to the wavelengths in Fig. 1. For example, an excitation with a wavelength of $18.4 \mathrm{~mm}$ is prescribed for a lower jet and the excitation wavelength in the Fig. 1 is of the order of $12 \mathrm{~mm}$.

The same can be seen on the second and third jets. At the second jet the excitation wavelength is $50 \mathrm{~mm}$ and the Fig. 1 shows the superposition of a prescribed wavelength and a wavelength close to the resonance one. At the third jet the excitation wavelength is equal to $168 \mathrm{~mm}$ and the Fig. 1 shows an evidence of shorter wavelengths, so that the prescribed wavelength does not have time to show itself. However, despite this we'll determine the comparative value of increments of jet decomposition into droplets.

The distance of jet decomposition for all images, as follows from Fig. 1, we will determine by a distance including several excitation wavelengths of the jet $N$. We assume that the instability increment of the lower jet decomposition in Fig. 1 is equal to $\gamma_{1}$. Then the distance of the lower jet decomposition is determined by the expression $\Delta l_{1}=N \lambda_{1} \approx V_{1} / \gamma_{1}$. The wavelength is $\lambda_{1}=4.6 \cdot 4=18.4 \mathrm{~mm}$ and the corresponding wavenumber $X_{1} \approx 2 \pi \cdot 2 / 4.6 \cdot 4=0.68$.

The distance of the second jet decomposition is determined by the expression $\Delta l_{2}=N \lambda_{2} \approx V_{1} / \gamma_{2}$. The excitation wavelength is $\lambda_{2}=12.5 \cdot 4=50 \mathrm{~mm}$ and the corresponding dimensionless wavenumber $X_{2} \approx 2 \pi \cdot 2 / 12.5 \cdot 4=0.25$. 
Then, on the basis of given estimates, the instability increment of the second jet decomposition is smaller than the increment of the lower jet by a factor of $\Delta l_{1} / \Delta l_{2} \approx 4.6 / 12.5 \approx 0.37$, i.e. is equal to $\gamma_{2} \approx \gamma_{1} \Delta l_{1} / \Delta l_{2}=\gamma_{1} \cdot 0.37$.

For the upper jet the instability increment of jet decomposition is less than the increment of the lower jet by a factor of $\Delta l_{1} / \Delta l_{3}=4.6 / 42 \approx 0.11$, i.e. it is equal to $\gamma_{3} \approx \gamma_{1} \Delta l_{1} / \Delta l_{3}=\gamma_{1} \cdot 0.11$ and the dimensionless wavenumber is of the order $X_{3} \approx 2 \pi \cdot 2 / 42 \cdot 4=0.08$.

If we assume that the lower jet is close to the resonant decomposition into droplets, this means that the value of the dimensionless increment is of the order of the maximum increment (24), which is realized at $X_{1}=0.7$. Numerical calculations show that the maximum increment (24) is reached at $G=2.24$, which corresponds to the water velocity $V_{1}=12.6 \mathrm{~cm} / \mathrm{s}$. Based on the above reasoning we determine from (24) the value of the maximum increment $\gamma_{K G}^{\max }=0.32479$.

Fig. 3 shows a dependence graph of the instability increment of jet decomposition (curve 1) obtained from the expression for the Rayleigh-Plateau instability increment (3). Dark markers on this graph indicate the values of instability increments obtained on the basis of the experimental data presented in Fig. 1. Light markers in Fig. 3 indicate the experimentally measured points describing the dependence of the dimensionless instability increment $Y(X)$ on the dimensionless wave number $X$ for ideal liquids [5]. The dependence of the dimensionless increment on the dimensionless wavenumber (curve 2) described by expression (24) is presented in Fig. 3 for comparison.

It follows from Fig. 3 that the theoretical model of jet decomposition described by formula (24) with no media viscosity corresponds closely in quantitative sense to the experimental results. Taking account of media viscosity, as follows from the solution of the Kelvin-Helmholtz problem in viscous media [11], can lead to a quantitatively different result.

In the next section we present the solution of the Rayleigh-Plateau problem in the Kelvin-Helmholtz formulation with allowance for the viscosity of both media.

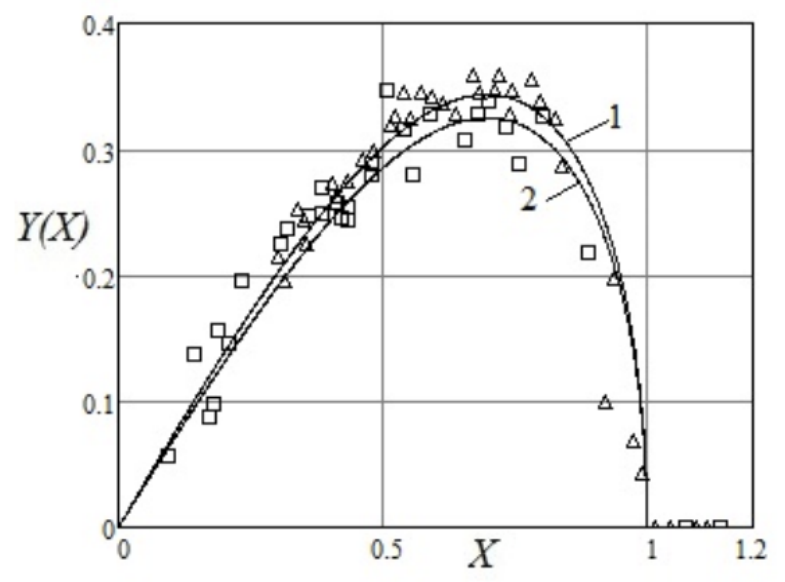

Figure 3. Dimensionless instability increment $Y(X)$ as a function of the dimensionless wavenumber $X$ for ideal liquids. Curve 1 corresponds to the dimensionless increment of Rayleigh-Plateau instability (3), curve 2 is given by expression (24).

\section{TAKING ACCOUNT OF MEDIA VISCOSITY EFFECT ON RAYLEIGH-PLATEAU INSTABILITY IN THE FORMULATION OF THE KELVIN-HELMHOLTZ PROBLEM Low viscosity media}

At dimensionless variables $G=\frac{\sigma}{V_{1}^{2} \rho_{1} R_{0}}, X=k R_{0}, Y=\omega \sqrt{G} \sqrt{\frac{\rho_{1} R_{0}^{3}}{\sigma}}$ the dispersion equation (21) takes the form:

$$
Y^{2}+2 i \frac{Y X}{\sqrt{G}} \frac{I_{1}(X)}{I_{0}(X)} \hat{\mu}_{1}\left(1+X \frac{K_{0}(X)}{K_{1}(X)}\right)-2 i \frac{X^{2}}{G} \frac{I_{1}(X)}{I_{0}(X)} \hat{\mu}_{2}\left(1-X \frac{I_{0}(X)}{I_{1}(X)}\right)+\frac{X^{2}}{G}\left(1-G X \frac{I_{1}(X)}{I_{0}(X)}\right)=0 .
$$

where, $\hat{\mu}_{1}=\frac{\mu_{1}}{R_{0} \rho_{1} V_{1}} ; \hat{\mu}_{2}=\frac{\mu_{2}}{R_{0} \rho_{1} V_{1}}$ - dimensionless coefficients of dynamic viscosity of the media 1 and 2 , respectively. The relationship between the dynamic viscosities of air and water $\hat{\mu}_{1} \gg \hat{\mu}_{2}$ and the relationship between velocities of media $V_{1}^{2} \gg V_{2}^{2}$ are taken into account in the expression (25).

Using the reasoning of the previous section on ideal water-air jet decomposition we can determine the characteristic parameters of the jet decomposition of viscous water-air media, provided that the ow velocity of water in 
the viscous case remains the same as in the ideal case. In numerical calculations of the increment in the expression (25) the following parameter values were chosen: $\hat{\mu}_{1}=2.17 \cdot 10^{-3} ; \hat{\mu}_{2}=3.91 \cdot 10^{-5}$, which correspond to the viscosity of water and air under normal conditions. The numerical analysis (25) shows that taking account of water and air viscosities does not significantly change the value of the instability increment compared with their ideal analogue and the range of unstable wavenumbers remains as before.

Thus, when taking into account the viscosity of water and air, the jet decomposition into droplets is possible within the range of wavenumbers $0<X \leq 1$, which corresponds to the jet diameters. The obtained criterion corresponds to Plato's experimental conclusion that the instability of the jet occurs when the length of the liquid column satisfies the condition $\lambda \geq 3.13 \cdot D$. The maximum increment is equal to $Y\left(X_{1}\right)=0.32391$, smaller in magnitude than for ideal media $Y\left(X_{1}\right)<\gamma_{K G}^{\max }$ and is achieved for perturbances with a wavelength $X_{\max }=0.7$.

Thus, the proposed model of decomposition of the viscous fluid jet into droplets corresponds to the experimental data; makes it possible to take into account the effect of viscosity on the jet decomposition velocity and to estimate the characteristic parameters of the process.

As we see, the instability increments in media with low viscosity differ slightly from increments for ideal media. Let us consider the instability of jet decomposition in media with a finite viscosity.

\section{The jet is characterized by a high viscosity and the ambient medium - by a low viscosity}

Let us consider the jets whose viscosities are not small. The description of jet instability with the Ohnesorge number $O h_{1}=\mu_{1} \rho_{1}^{-1} \sqrt{\rho_{1} /\left(\sigma R_{0}\right)}=0.58$ [5] by expression (25) shows that the curve with parameters $\hat{\mu}_{1}=0.39 \gg \hat{\mu}_{2} \approx 7.0 \cdot 10^{-5}$ has the smallest departure from the experimental data. Based on the condition for the development of instability $0<X \leq 1$ an optimal value of the parameter $G=0.45$ is calculated. Value of the increment determined by the equation (25) relative to the experimental data (curve 2) is shown in Fig. 4.

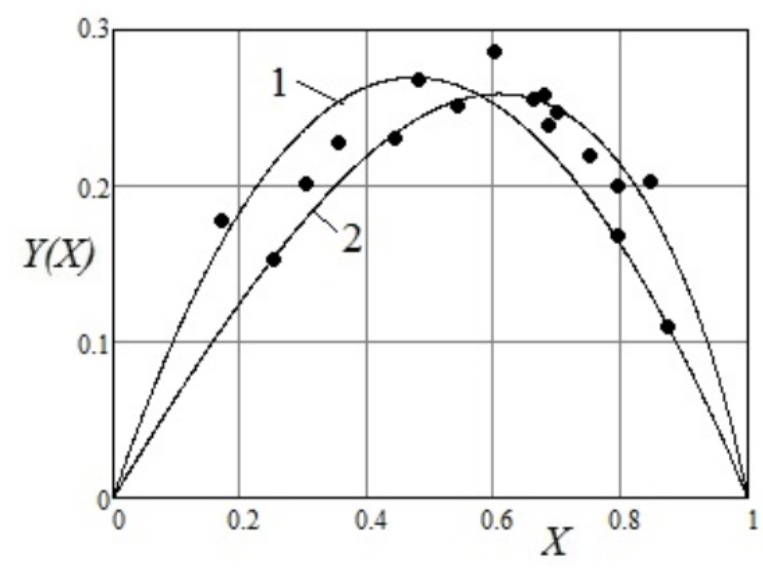

Figure 4. Dimensionless instability increment of decomposition of a viscous liquid jet in the air $Y(X)$ for $O h_{1}=0.58$ as a function of the dimensionless wavenumber $X$ (curve 1, [3]). Curve 2 corresponds to the increment (25). Experimental points are shown by markers [5].

From the comparison of curves 1 and 2 in Fig. 4 it follows that taking account of the high viscosity of the jet in the expression for the increment (25) makes it possible to describe the experimental results with a sufficiently high degree of accuracy. For liquid densities $\rho_{2}<<\rho_{1}$ the relationship $O h_{2}<<O h_{1}$ is satisfied. The interval of unstable wavenumbers remains the same $0<X \leq 1$.

\section{The jet and the ambient medium are characterized by a high viscosity}

In the case $\hat{\mu}_{1}>\hat{\mu}_{2} \sim 1$ the instability increment is determined by the expression (25), since we believe that $V_{1}^{2}>V_{2}^{2}$ as before. The result of the numerical calculation of the instability increment of jet decomposition obtained from equation (25) with allowance for viscosity in both media is shown in Fig. 5. The Ohnesorge number $O h_{1}=0.58$ and the following parameter values are used for calculations:

- $\hat{\mu}_{1}=1.83 ; \hat{\mu}_{2}=1.64, G=10$ - follows from the condition for instability development $0<X \leq 1$ (curve 2 , Fig. 5);

- $\hat{\mu}_{1}=1.83 ; \hat{\mu}_{2}=1.8, G=16$ - follows from the condition for instability development $0<X \leq 1$ (curve 3 , Fig. 5). 


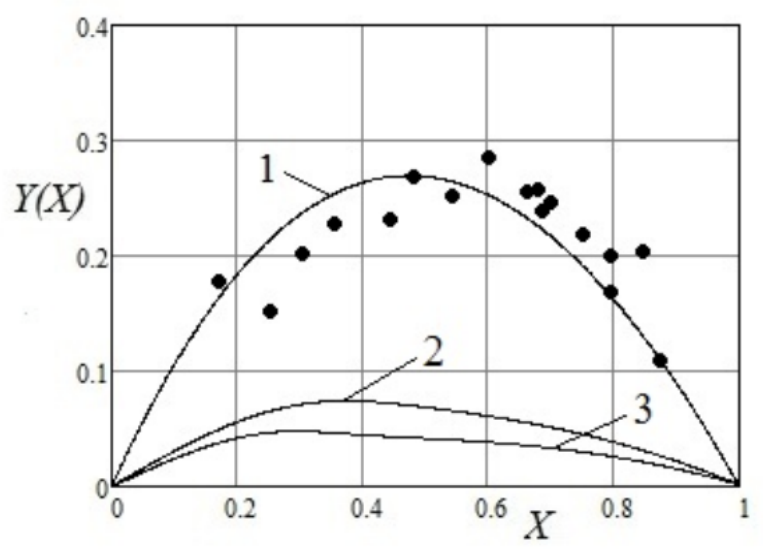

Figure 5. Dimensionless instability increment of viscous fluid jet decomposition in a viscous medium as a function of the dimensionless wavenumber $X$ for $O h_{1}=0.58$ and parameters: curve $2-\hat{\mu}_{1}=1.83 ; \hat{\mu}_{2}=1.64 ;$ curve $3-\hat{\mu}_{1}=1.83 ; \hat{\mu}_{2}=1.8$. Curve 1 corresponds to curve 1 of Fig. 4 .

From numerical calculations it follows that with the same Ohnesorge numbers for the jet $O h_{1}$ the instability increment decreases with increasing viscosity of the ambient medium $\hat{\mu}_{2}$. At a constant viscosity of the ambient medium the instability increment is greater there, where the jet viscosity is greater. This conclusion is in contrast to the theoretically obtained conclusion about decrease in the instability increment with increase in the jet viscosity [5]. This contradiction is associated probably with the specificity of the boundary conditions used at derivation of the dispersion equation.

\section{CONCLUSIONS}

In this paper the theoretical solution of the Rayleigh-Plateau problem about the instability of a freely falling uid jet is compared with the available experimental results. The mismatch of the theory with the experiment was revealed. In this case taking account of the jet viscosity does not significantly improve the agreement of the theory with the experiment. Therefore, it was proposed to investigate the Rayleigh-Plateau instability in the formulation of the KelvinHelmholtz problem with percolation boundary conditions with allowance for the viscosity of the contacting media. A dispersion equation was obtained taking account of the viscosity of both media for percolation boundary conditions. It was shown that for viscous jets and a weakly viscous ambient medium the instability increment describes the experimental results with a sufficiently high degree of accuracy. Numerical calculations show that for jets with the same viscosity the instability increment decreases with increasing viscosity of the ambient medium. If the viscosity of the ambient medium is constant, then the instability increment will be greater where the viscosity of the jet is greater.

\section{ORCID IDs}

Doksana L. Andreeva, https://orcid.org/0000-0001-9757-8519; DLeonid A. Bulavin, https://orcid.org/0000-0002-8063-6441

(D)Viktor I. Tkachenko, https://orcid.org/0000-0002-1108-5842

\section{REFERENCES}

[1] J. Plateau, Experimental and Theoretical Statics of Liquids Subject to Molecular Forces Only, (Memoires of the Academy of Belgium, 1873).

[2] Lord Rayleigh F.R.S., Proc. Lond. Math. Soc. 1-10(1), 4 (1878), https://doi.org/10.1112/plms/s1-10.1.4.

[3] J.W. Strutt (Lord Rayleigh), Phil. Mag. 34(5), 177 (1892), https://doi.org/10.1080/14786449208620301.

[4] S.K. Aslanov, Technical Physics. The Russian Journal of Applied Physics. 44, 1386 (1999).

[5] J. Eggers, E. Villermaux, Rep. Prog. Phys. 71, 1 (2008), http://dx.doi.org/10.1088/0034-4885/71/3/036601.

[6] S.O. Shiryaeva, and A.I. Grigoriev, Электронная библиотека материалов [Electronic Library of Materials], 50(5), 24 (2014).

[7] W.V. Ohnesorge, Z. Angew. Math. Mech. 16, 355 (1936), https://doi.org/10.1002/zamm.19360160611.

[8] H. Helmholtz, Annalen der Physik, 277, 641 (1890), https://doi.org/10.1002/andp.18902771202.

[9] W. Thomson (Lord Kelvin), Phil. Mag. 42, 362 (1871), https://doi.org/10.1080/14786447108640585.

[10] S. Chandrasekhar, Hydrodynamic and Hydromagnetic Stability (Dover publications Inc., New York, 1981).

[11] V.I. Tkachenko, The Journal of Kharkiv National University, physical series "Nuclei, Particles, Fields", 916, 70-74 (2011), http://dspace.univer.kharkov.ua/handle/123456789/4736. (in Russian)

[12] M. van Dike, Альбом течений жидкости и газа [Album of fluid and gas flows], (Mir, Moscow, 1986). (in Russian)

[13] D.S. Kuznetsov, Специальные функичии, [Special functions], (Vysshaya shkola, Moscow, 1962). (in Russian)

[14] I.K. Kikoin, (Ed.), Таблицы физических величин. Справочник [Tables of physical quantities. Reference book.], (Atomizdat, Moscow, 1976). (in Russian) 


\author{
ДИСИПАТИВНА НЕСТІЙКІСТЬ РЕЛЕЯ-ПЛАТО \\ Оксана Л. Андрєєва ${ }^{\text {a,b }}$, Леонід А. Булавін ${ }^{\text {, Віктор І. Ткаченко }}$ \\ ${ }^{a}$ ННЦ "Харківський фізико-технічний інститут" \\ вул. Академічна, 1, 61108, Харків, Україна \\ ${ }^{b}$ Харківський Наиіональний університет імені В.Н. Каразіна, Харків, Украйна \\ пл. Свободи, 4, 61022, Харків, Украӥна \\ ${ }^{c}$ Київський Національний університет імені Тараса Шевченка \\ вул. Володимирська 64/13, 01601, Киї, Україна
}

Розглянуто нестійкість струменя рідини, що вільно падає, в повітрі при врахуванні в'язкості середовищ, що контактують. У нехтування в'язкості обох середовищ нестійкість досліджена в роботах Релея і Плато. Вони показали, що нестійкість розвивається в результаті дії поверхневих сил, і виражається в зміні циліндричної форми границі струменя рідини, що вільно падає, з повітрям на послідовність сферичних крапель. У наступних роботах, шляхом феноменологічного врахування в'язкості за допомогою числа Онзагера, показано, що на показники нестійкості впливає в'язкість кожної 3 контактуючих середовищ. Однак такий метод обліку в'язкості є не зовсім коректним, тому що не враховує специфіку граничних умов, існуючу на кордоні розділу середовищ. В роботі запропоновано використовувати перколяційні граничні умови, правомірність яких доведена на прикладі точного визначення порогової швидкості виникнення нестійкості КельвінаГельмгольца. Для задачі Релея-Плато з перколяційними граничними умовами отримано дисперсійне рівняння, яке описує нестійкість при врахуванні в'язкості обох середовищ. Обгрунтовано дисипативний характер розвитку таких нестійкостей. Визначено інкремент розвитку нестійкості у випадках, коли: струмінь і середовище мають малу в'язкість (ідеальні рідини); струмінь характеризується великою в'язкістю, а навколишнє середовище - малою; струмінь і навколишнє середовище характеризуються великою в'язкістю. Показано, що теоретична модель краплинного розпаду струменя у відсутність в'язкості обох середовищ досить добре, в кількісному відношенні, відповідає експериментальним результатам. Максимальний інкремент дорівнює $\gamma_{K G}^{\max } \approx 0.32$, проти инкремента Релея-Плато $\gamma_{R P}^{\max } \approx 0.34$, для збурень 3 однаковим хвильовим числом $X_{\max } \approx 0.7$. Показано також, що для вузьких струменів і слабов'язкого навколишнього середовища інкремент нестійкості 3 досить високим ступенем точності описує експериментальні результати. Числові розрахунки показують, що для струменів з порівнянною в'язкістю інкремент нестійкості зменшується з ростом в'язкості навколишнього середовища. У разі, якщо в'язкість навколишнього середовища постійна, то інкремент нестійкості буде більше там, де більше в'язкість струменя. Показано, що результати теоретичних розрахунків добре узгоджуються 3 наявними експериментальними даними.

КЛЮЧОВІ СЛОВА: нестійкість Релея-Плато, поверхневий натяг, в'язкість, перколяційні граничні умови, дисипативна нестійкість, інкремент нестійкості, хвильове число, інтервал нестійкості.

\author{
ДИССИПАТИВНАЯ НЕУСТОЙЧИВОСТЬ РЭЛЕЯ-ПЛАТО \\ Оксана Л. Андреева ${ }^{a, b}$, Леонид А. Булавин ${ }^{\text {, Виктор И. Ткаченко }}{ }^{\text {a,b }}$ \\ ${ }^{a}$ ННЦ "Харьковский физико-технический институт" \\ ул. Академическая, 1, 61108, Харьков, Украина \\ ${ }^{b}$ Харьковский начиональный университет имени В.Н. Каразина, Харьков, Украина \\ пл. Свободьь, 4, 61022, Харьков, Украина \\ ${ }^{c}$ Киевский Национальный университет имени Тараса Шевченко \\ ул. Владимирская 64/13, 01601, Киев, Украина
}

Рассмотрена неустойчивость свободно падающей струи жидкости в воздухе при учете вязкости контактирующих сред. В пренебрежении вязкостей обеих сред неустойчивость исследована в работах Рэлея и Плато. Они показали, что неустойчивость развивается в результате действия поверхностных сил, и выражается в изменении цилиндрической формы границы свободно падающей струи жидкости с воздухом на последовательность сферических капель. В последующих работах, путем феноменологического учета вязкости посредством числа Онзагера, показано, что на характер неустойчивости влияет вязкость каждой из контактирующих сред. Однако такой метод учета вязкости является не совсем корректным, т.к. не учитывает специфику граничных условий, существующую на границе раздела сред. В работе предложено использовать перколяционные граничные условия, правомерность которых доказана на примере точного определения пороговой скорости возникновения неустойчивости Кельвина-Гельмгольца. Для задачи Рэлея-Плато с перколяционными граничными условиями получено дисперсионное уравнение, которое описывает неустойчивость при учете вязкости обеих сред. Обоснован диссипативный характер развития таких неустойчивостей. Определены инкременты развития неустойчивостей в случаях, когда: струя и среда имеют малую вязкость (идеальные жидкости); струя характеризуется большой вязкостью, а окружающая среда - малой; струя и окружающая среда характеризуются большой вязкостью. Показано, что теоретическая модель капельного распада струи в отсутствие вязкости обеих сред достаточно хорошо, в количественном отношении, соответствует экспериментальным результатам. Максимальный инкремент равен $\gamma_{K G}^{\max } \approx 0.32$, против инкремента Рэлея-Плато $\gamma_{R P}^{\max } \approx 0.34$, для возмущений с одинаковым волновым числом $X_{\max } \approx 0.7$. Показано также, что для вязких струй и слабовязкой окружающей среды инкремент неустойчивости с достаточно высокой степенью точности описывает экспериментальные результаты. Численные расчеты показывают, что для струй с сравнимой вязкостью инкремент неустойчивости уменьшается с ростом вязкости окружающей среды. В случае, если вязкость окружающей среды постоянна, то инкремент неустойчивости будет больше там, где больше вязкость струи. Показано, что результаты теоретических расчетов хорошо согласуются с имеющимися экспериментальными данными.

КЛЮЧЕВЫЕ СЛОВА: неустойчивость Рэлея-Плато, поверхностное натяжение, вязкость, перколяционные граничные условия, диссипативная неустойчивость, инкремент неустойчивости, волновое число, интервал неустойчивости. 